worth considering when cholestatic hepatitis is suspected. In such patients the administration of prednisone $(40 \mathrm{mg}$. daily) results, with few exceptions, in a prompt lowering of the serum bilirubin. If this occurs steroid therapy should be continued into convalescence, for otherwise a relapse may occur. In drug cholestasis there is usually little effect. In extrahepatic obstruction the fall, if it occurs at all, is smaller, and there is a prompt return to the initial level on discontinuing prednisone unless the test has happened to coincide with spontaneous relief of jaundice in a patient with an ampullary neoplasm or gallstones.

\section{Immunofluorescent Test}

This test, which depends on the presence in the serum of a non-organ specific cytoplasmic antibody directed against a mitochondrial antigen, is positive in most patients with primary biliary cirrhosis. Positive reactions are also obtained in about a quarter of patients with active chronic hepatitis or

TABLE II.-Incidence of Serum Antibodies in Chronic Liver Disease

\begin{tabular}{l|c|c|c}
\hline & \multicolumn{2}{|c|}{ Incidence of Antibodies $(\%)$} \\
\cline { 2 - 4 } & $\begin{array}{c}\text { Antinuclear } \\
(>1 / 20)\end{array}$ & $\begin{array}{c}\text { Smooth } \\
\text { muscle }\end{array}$ & Mitochondrial \\
\hline Active chronic hepatitis & 56 & 67 & 23 \\
Primary biliary cirrhosis & 31 & 50 & 94 \\
Cryptogenic cirrhosis & 16 & 28 & 25 \\
Alcoholic cirrhosis & 7 & 0 & 0 \\
\hline Main duct obstruction & 0 & 0 & 3 \\
\hline
\end{tabular}

Results of various studies (data of Walker et al. ${ }^{34}$ ) post-necrotic cirrhosis. In main duct obstruction, and in drug or viral hepatitis, positive reactions of low titre are obtained only occasionally (Table II).

\section{Percutaneous Cholangiography}

If the diagnosis is still in doubt and laparotomy is being considered this should be preceded by a percutaneous transhepatic cholangiogram. In this technique a fine polyethylene catheter is inserted into the liver under local anaesthesia. If the intrahepatic ducts are dilated from extrahepatic obstruction they are easy to puncture, and the picture obtained after injection of contrast medium will define the site and nature of the obstruction. The technique is particularly useful in showing the presence of strictures or fistulae and in demonstrating the small hepatic duct carcinoma situated in the porta hepatis, which can be missed even at surgery (Fig. 6 and 7). Once a bile duct has been punctured, there is a risk of a bile leak, and laparotomy should follow within a few hours. In intrahepatic cholestasis the ducts are not dilated and usually bile cannot be aspirated. Unfortunately, occasional patients with partial extrahepatic biliary obstruction do not have dilated ducts, and so, like any test, it is not perfect.

Irreversible liver failure can be precipitated by laparotomy in patients with jaundice due to hepatitis, and a good general rule is not to operate within two weeks of the onset of jaundice, however certain the diagnosis appears, unless there is definite evidence of cholangitis. Moreover, with few exceptions, only palliative operations are possible for biliary obstruction due to carcinoma, and the chances of an operable lesion becoming inoperable during an adequate period of evaluation must be very small indeed.

\title{
Surgical Aspects
}

\section{J. L. DAWSON, $\ddagger$ M.S., F.R.C.S.}

\section{Preoperative Preparation}

Two special hazards face a patient with obstructive jaundice undergoing an operation; firstly, bleeding because of prothrombin deficiency, and, secondly, postoperative renal failure. The bleeding diathesis is easily corrected by the administration of a vitamin $\mathrm{K}$ analogue given by injection for a few days before operation. It is now recognized that the risk of postoperative renal failure, and indeed deaths from all causes, is directly related to the depth of the jaundice..$^{35}$

The mechanism of the postoperative renal failure has been investigated both experimentally using the rat and clinically. 3637 Experiments were planned to observe the effect of 60-minute renal ischaemia in jaundiced animals and to compare it with the changes observed in controls. The difference was striking; renal ischaemia was poorly tolerated in the presence of obstructive jaundice and fatal tubular necrosis developed in nine out of 14 animals in this group but in none of the 13 in the control group. A further group of jaundiced animals was studied in whom a mannitol diuresis established just before a period of 60 minutes of renal ischaemia. In this group the amount of renal damage was much less severe and was similar to that observed in the nonjaundiced group.

More recently Gunn rats were used in similar experiments. ${ }^{38}$ The Gunn rat has a congenital unconjugated hyperbilirubinaemia; after duct ligation the serum bilirubin level remains unchanged, but bile salt retention occurs. Sixty minutes of renal ischaemia produced identical mild changes in the two groups with and without bile-duct obstruction. Thus neither unconjugated bilirubin nor bile salts seem to be responsible for the renal sensitivity to ischaemia in jaundice. The most likely substance seems to be conjugated bilirubin.

Sequential renal function studies were made in 12 patients undergoing upper abdominal surgery ${ }^{37}$ and the results were compared with those obtained from 15 jaundiced patients undergoing laparotomy. A greater fall in creatinine clearance was observed in the jaundiced group, which was maximal in the mostly deeply jaundiced patients. In a further seven deeply jaundiced patients a mannitol diuresis was initiated just before operation and in these the excessive fall in creatinine clearance was prevented.

Thus on both clinical and experimental grounds prophylactic mannitol should be given to jaundiced patients undergoing surgery-and certainly in all those in whom the serum bilirubin level is over $15 \mathrm{mg} . / 100 \mathrm{ml}$. Possibly large volumes of intravenous Ringer's lactate or glucose saline solution would have the same effect. Nevertheless, it is less easy to maintain high urine flows with these solutions and dangerous fluid retention may occur; ${ }^{39}$ whereas mannitol easily breaks through the postoperative antidiuresis and promotes a high flow of dilute urine. No complications have been encountered using mannitol in the following regimen:

$500 \mathrm{ml} .10 \%$ mannitol infused beginning one hour before operation and $5 \%$ mannitol given in the postoperative period sufficient to maintain the urine flow above $1 \mathrm{ml}$./min. for 48 hours. This usually requires $500-1,000 \mathrm{ml}$. in each 24 hour period. 


\section{Value of Percutaneous Cholangiography}

A percutaneous cholangiogram is of great value in demonstrating the anatomical site of the extrahepatic block, especially in a patient with a bile duct stricture in whom previous surgery usually makes the dissection tedious and difficult. In malignant obstruction of the lower end of the duct the gall bladder may fail to fill but this does not necessarily mean that it is unsatisfactory to use in a bypass operation. It seems that the contrast medium cannot enter the tense dilated gall bladder.

Some authors recommend performing a routine coeliac axis arteriogram and splenic venogram on patients suspected of having a pancreatic neoplasm. ${ }^{40}$ Tumours may produce narrowing or distortion of adjacent vessels and when the films are considered with the percutaneous cholangiogram it is possible to predict with $90 \%$ accuracy whether or not a pancreatic tumour is resectable.

\section{Management of Ascending Cholangitis}

Ascending cholangitis develops only if there is biliary obstruction, usually due to gall stones. It is a serious condition, for a few patients rapidly deteriorate and may die despite all efforts at resuscitation. ${ }^{4142}$ The infection may lead to Gramnegative septicaemia, deepening jaundice, and finally oliguric renal failure. All patients must be carefully observed, and a blood culture should be taken as soon as possible because an accurate bacteriological diagnosis may be lifesaving if the result is available in time. Unfortunately many patients present in a critical state so that antibiotic therapy has to be started without knowing the organism's sensitivity.

Biliary obstruction may severely limit the penetration of various antibiotics into the bile. Ampicillin is probably ineffective in the presence of duct obstruction. ${ }^{43}$ In a careful study of various antibiotic concentrations in the bile and gall bladder wall intramuscular or intravenous rifamycin was found to be the most effective agent, ${ }^{44}$ though there is relatively little clinical experience of this agent for treating cholangitis and several cases of cholestatic jaundice have been reported.

Regular measurements of the central venous pressure should be made and hourly urine volumes charted. Large volumes of colloid are often required to maintain the circulatory volume in patients with Gram-negative septicaemia; mannitol should be given if necessary to maintain the urine flow above $1 \mathrm{ml}$./ min. Massive doses of chemotherapy should be given.

If there is no definite improvement within 36 to 48 hours then emergency operation to establish biliary drainage offers the only chance of controlling the source of the infection. In these patients who are desperately ill $T$-tube drainage of the common duct may be lifesaving. A definitive removal of stones and the gall bladder may be done at a later date.

\section{Obstructive Jaundice due to Gall Stones}

Cholecystectomy and exploration of the common bile duct is the accepted treatment for obstructive jaundice due to gall stones. In patients who have soft stones or sludge in the duct, or who are undergoing reoperation on the bile ducts, many surgeons would recommend an additional procedure to prevent recurrent stones such as sphincteroplastyts or choledochoduodenostomy: 47 Many so-called recurrent stones in the common bile duct are overlooked stones; careful radiological examination of the duct before exploration does much to decrease this error. Pre-exploratory $x$-ray films of bile duct yield accurate information about the number of stones and their size, and should always be taken. Unfortunately a T-tube cholangiogram immediately after exploration may be misleading as air bubbles are difficult to eliminate and the contrast may fail to flow into the duodenum though there is no organic block.
The bile from the common duct should always be sent for bacteriological culture, for in one series $64 \%$ of asymptomatic patients were found to have a positive culture. ${ }^{48} \mathrm{~A}$ precise bacteriological diagnosis may prove invaluable in the occasional patient who develops septicaemia after exploration of the common duct.

Theoretically considerable trouble from ascending cholangitis might be expected after choledochoduodenostomy

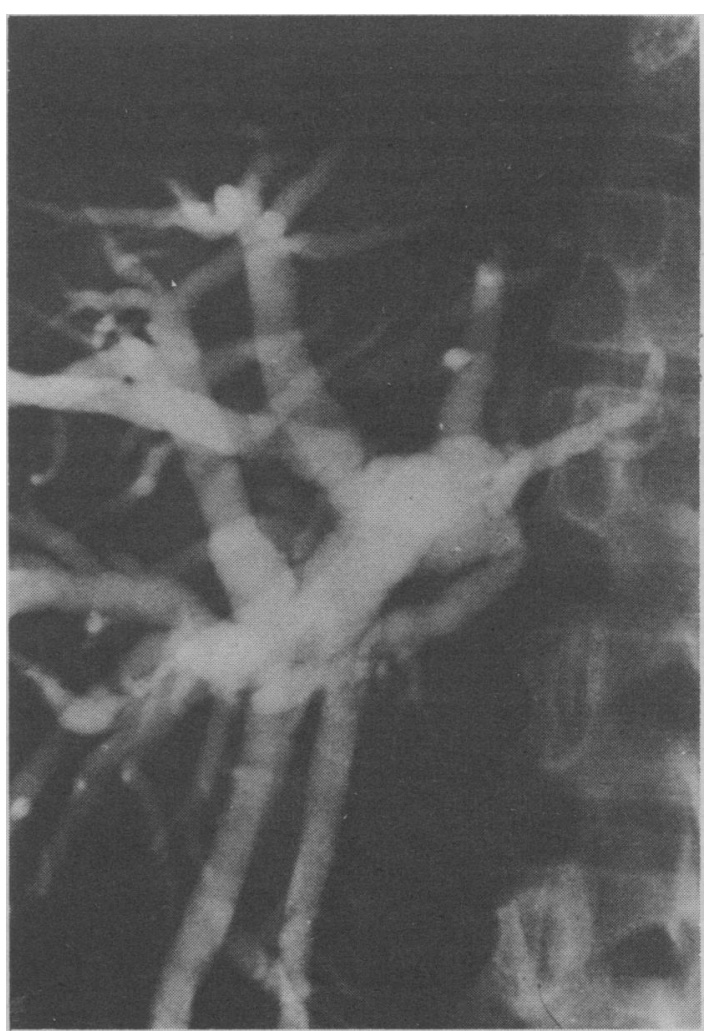

FIG. 6.-Percutaneous transhepatic cholangiography showing obstruction in the porta hepatis by carcinoma of the hepatic duct in a man aged 32 who presented with many of the features of infective hepatitis.

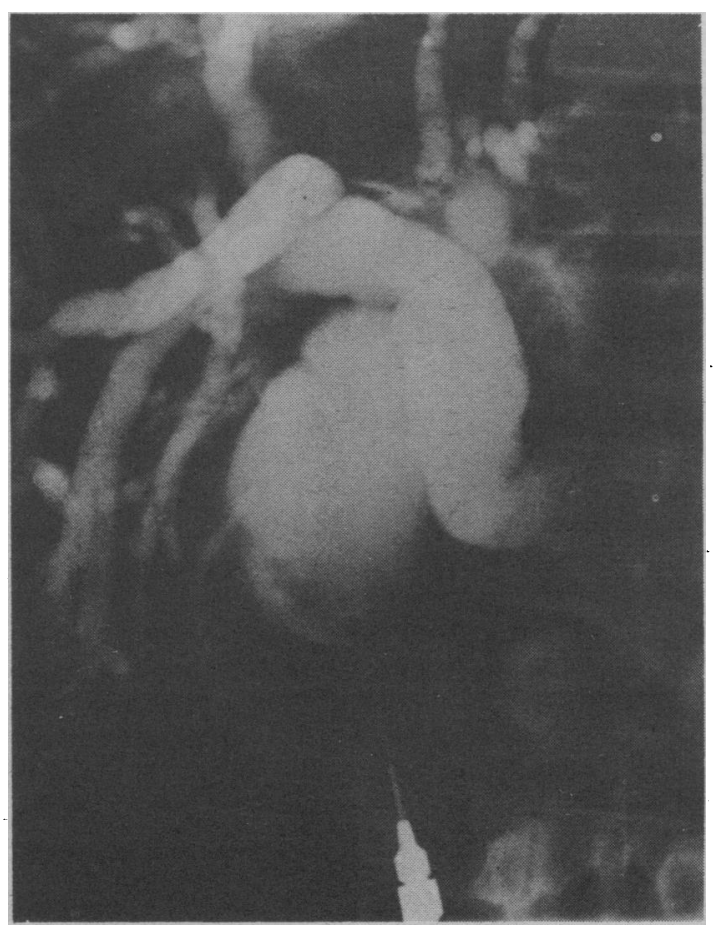

Fig. 7.-Obstruction at lower end of common bile duct by carcinoma of the pancreas in man aged 41 in whom the diagnosis had been made difficult by the giving of a chlorpromarine-like drug shortly before the onset of jaundice. 
but, provided the stoma is at least $2.5 \mathrm{~cm}$. long, this seems to occur only rarely in most reported series. ${ }^{47}$ It is claimed that though reflux of intestinal contents occurs cholangitis does not develop because there is no obstruction at the stoma.

\section{Bile Duct Strictures}

In the repair of biliary stricture the proximal duct usually has to be anastomosed to a Roux loop of jejunum because the distal duct is destroyed. Accurate mucosal apposition is of paramount importance if the stricture is not to recur. Various techniques have recently been described which facilitate this. ${ }^{49}$ A jejunal mucosal graft taken from a Roux loop is carried up to the hilum of the liver over a T-tube where it lies in apposition with the ends of the right and left hepatic ducts. If the common hepatic duct is not completely destroyed then the anastomosis is more accurately constructed from within the lumen of the jejunum, leaving the suturing of the end of the Roux loop until last. After common hepatic duct repair transhepatic splinting simplifies the problem of keeping the tube in the correct position. Splinting is usually maintained for about six months. ${ }^{50}$

\section{Carcinomas}

Many carcinomas of the bile ducts and ampulla of vater are relatively slow growing and should be resected whenever possible-even intubation of a carcinoma of the common bile duct may completely relieve the jaundice and itching for several years. Pancreaticoduodenectomy for ampullary lesions is well worth while, as it results in an appreciable five-year survival rate- $39 \%$ in one series. ${ }^{.1}$

The natural history of carcinoma of the pancreas is usually short. The average survival after a biliary-intestinal anastomosis to relieve jaundice is only about five months; even patients with a small mobile tumour that is not resected have an average survival of only eight months. ${ }^{52}$ After pancreaticoduodenectomy most series report an average survival of about one year, but a five-year survival rate of less than $5 \%$. Nevertheless, it is claimed that these patients are spared the intractable pain of an advanced pancreatic cancer.

In experienced hands the mortality rate of pancreaticoduodenectomy is low-for example, 41 consecutive operations without a death ${ }^{53}$ - but in inexperienced hands it can be as high as $40 \%,{ }^{54}$ The main causes of this mortality rate are haemorrhage at operation, and postoperative fistulae, gastrointestinal haemorrhage from a marginal ulcer, and renal failure. Uncontrollable haemorrhage at operation usually results from attempts to resect an unresectable tumour. Postoperative biliary fistulae may be minimized by the use of a $\mathrm{T}$ tube to drain the bile duct. Pancreatic fistulae are prevented by the use of a fine polyethylene cannula to drain the pancreatic duct externally for a few days, thus allowing the anastomosis to heal. A vagotomy and antrectomy is the logical way to minimize postoperative bleeding from a gastrojejunal ulcer. The use of mannitol and careful observation of the urine output should decrease the problem of postoperative renal failure:

In patients with a carcinoma of the head of pancreas a careful trial dissection is done to ensure that the portal vein is not involved, and that the tumour is confined to the head of the pancreas. Any enlarged adjacent lymph nodes may be examined by the frozen section technique. Pancreaticoduodenectomy is reserved for those patients in whom the nodes are free of deposits and the tumour easily resectable. In the remainder a palliative bypass operation to relieve jaundice, and perhaps duodenal obstruction, is done.

\section{REFERENCES}

1 Barrett, P V. D., Cline, M. J., and Berlin, N. I., fournal of Clinical Investigation, 1966, 45, 1657.

2 Blumenschein, S. D., Kallen, R. J., Storey, B., Natzschka, C., Odell, G. B.. and Childs, B., Pediatrics, 1968, 42, 786.

3 Fulop, M., and Sandson, J., Clinical Science, 1967, 33, 459.

4 Levi, A. I., Gatmaitan, Z., and Arias, I. M., Lancet, 1969, 2, 139.

5 Gartner, L. M., and Arias, I., New England fournal of Medicine, 1969, 280, 1339.

'Black, M.. and Billing, B. H., New England fournal of Medicine, 1969, $280,1266$.

7 Lester, R., and Troxler, R. F., Gastroenterology, 1969, 56, 143.

8 Adlard. B., and Lathe, G. H., Paper presented at the IV Meeting of the European Association of the Study of Liver, 1969

9 Platt. D. S., and Cockrill, B. L., Biochemical Pharmacology, 1968, 18, 459.

10 Popper. H.. Annual Review of Medicine, 1968, 19, 39.

11 Schnaffer, F., and Popper, H., Lancet, 1969, 2, 355.

12 Javitt, N. B., Gastroenterology, 1969, 56, 622.

13 Hart, L. G.. Guarino, A. M., and Adamson, R. H., American fournal of Physiology, 1969, $217,46$.

14 Thompson, R. P. H., and Williams, R., Postgraduate Medical fournal, 1969. 45, 196.

15 Forker, E. L., fournal of Clinical Investigation, 1969, 48, 654.

16 Blumberg, B. S., Alter, H. I., and Visnich, S., Journal of the American Medical Association, 1965. 191, 541.

17 London. W. T., Sutnick, A. I., and Blumberg, B. S., Annals of Internal Medicine, $1969,70,55$.

18 Gocke, D. J., Greenburg, H. B., and Kavey, N. B., Lancet, 1969, 2, 248.

19 Turner, G. C., and White. G. B. B., Lancet, 1969, 2. 121.

2n Sutnick, A. I., London, W. T., Gerstley, B. J. S., Cronlund, M. M., and Blumberg, B. S., Fournal of the American Medical Association, 1968, 205, 670

21 Wright, R., McCollum, R. W., and Klatskin, G., Lancet, 1969, 2, 11. 22 De Groote, J. et al., Lancet, 1968, 2. 626.

23 Copenhagen Study Group, Lancet, 1969, 1, 119.

21 Mistilis, S. P., and Blackburn, C. R. B., Australasian Annals of Medicine, 1967. 16. 305.

25 Catz. C., and Yaffe, S. J., Pediatric Research, 1968, 2, 361.

26 Trolle, D., Lancet, 1968, 1, 251.

27 Ramboer, C., Thompson, R. P. H., and Williams, R., Lancet, 1969, 1, 966.

22 Ycung, C. Y., and Field, E., Lancet, 1969, 2, 135

29 Davies, P. A., Lancet, 1969, 2, 273.

30 Thompson, R. P. H., Stathers, G. M., Pitcher, C. W. T., McLean, A. E. M., Robinson, J., and Williams, R., Lancet, 1969, 2, 4.

31 Sherlock, S., British Medical fournal, 1968, 3, 515.

32 Drugs and Therapeutics Bulletin, 1968, 6, 81.

33 Williams, R., in Fourth Symposium on Advanced Medicine, edited by O. Wrong. London, Pitman Medical Publishing Co. Ltd., 1968.

34 Walker, J. G., Doniach, D., Roitt, I. M., and Sherlock, S., in The Liver, Walker, J. G., Doniach, D., Roitt, I. M., and Sherlock, S.
edited by A. E. Read. London, Butterworths, 1967.

35 Dawson, J. L., Annals of the Royal College of Surgeons of England, $1968,42,163$.

36 Dawson, J. L., British Medical fournal, 1964, 1, 810

37 Dawson, J. L., British Medical fournal, 1965, 1, 82.

38 Baum. M., Stirling, G. A., and Dawson, J. L., British Medical fournal, $1969,2,229$.

39 Mackenzie, A. I., and Donald, J. R., British Medical fournal, 1969, 3, 619.

40 Sato, T., Saitoh, Y., Koyama, K., and Watanabe, K., Annals of Surgery, 1968, 168, 876.

41 Williams, R, and Dawson, J. L., Proceedings of the Royal Society of Medicine, 1969, 62, 243.

42 Hinchey, E. J., and Couper, C. E., American fournal of Surgery, 1969, $117,62$.

43 Mortimer, P. R., Mackie, D. B., Haynes, S., British Medical fournal, $1969,3,88$.

44 Acocella, G., Mattiussi, R., Nicolis, F. B., Palanza, R., Tenconi, L. T., Gut, 1968, 9, 536.

45 Rothwell-Jackson, R. L., British fournal of Surgery, 1968, 55, 616.

46 Wright, N. L., British fournal of Surgery, 1968, 55, 33.

47 Madden, J. L., Gruwez, J. A., and Tan, P. Y., American fournal of Surgery, 1965, 109, 89.

4 Flemma, R. J., Flint, L. M., Osterhout, S., Shingleton, W. W., Annals of Surgery, 1967, 166, 563.

49 Smith, R., in Operative Surgery, 2nd edition, part 4, edited by C. Rob and R. Smith. London, Butterworths, 1969.

50 Smith, R., British fournal of Surgery, 1964, 51, 186

51 Mongé, J.' J., Judd, E. S., and Gage, R. P., Annals of Surgery, 1964, 160,711 .

52 Mongé, J. J., Annals of Surgery, 1967, 166, 908.

53 Howard, J. M., Annals of Surgery, 1968, 168, 629.

54 Nardi, G. L., American Surgeon, 1967, 33, 105. 